\title{
Rewarming preterm infants on a heated, water filled mattress
}

\author{
I SARMAN,* G CAN, $\dagger$ AND R TUNELL* \\ ${ }^{*}$ Department of Paediatrics, Huddinge Hospital, Karolinska Institute, Huddinge, Sweden and †Department \\ of Paediatrics, Faculty of Medicine, Capa Hospital, Istanbul, Turkey
}

SUMmARY Sixty low birthweight infants (1000-2000 g) admitted to a neonatal care unit in Turkey were studied. Those not requiring intensive care were randomly assigned for treatment either in a cot on a heated, water filled mattress kept at $37^{\circ} \mathrm{C}(\mathrm{n}=28)$ or in air heated incubators with a mean air temperature of $35^{\circ} \mathrm{C}(\mathrm{n}=32)$. On admission $53(88.3 \%)$ of the infants had body temperatures between $30^{\circ}$ and $36^{\circ} \mathrm{C}$. There was good correlation between axillary and rectal temperatures in the infants while they were hypothermic. Normal temperatures were achieved within the first day and remained within this range during the subsequent days after admission in all the infants treated on the heated, water filled mattress, whereas they were not achieved until three days later in the incubator group. The neonatal mortality among those treated on the heated, water filled mattress was $21 \%$, and among those treated in the incubator $34 \%$. The heated, water filled mattress provides a good alternative to skin to skin contact with the mother, and to the use of a complex and expensive incubator for rapidly attaining and maintaining normal temperatures in the low birthweight newborn.

Hypothermia and cold injuries were among the main causes of neonatal death in the early 19th century. ${ }^{1}$ The influence of thermal environment on the survival of premature newborn babies was clearly shown in the late $1950 \mathrm{~s}^{2}$ Since then physiological studies have defined the physical environment for nursing newborn infants in incubators and have identified the critical environmental temperatures for the care of various groups of newborn infants. ${ }^{34}$ Though the problem of neonatal hypothermia no longer exists in industrialised countries, there is evidence that it is still a serious threat to the lives of low birthweight infants in many developing countries, including those in the tropics. ${ }^{56}$ The incidence of neonatal hypothermia is, however, unknown in many countries; this lack of information may be caused by unawareness of the problem because of the higher priorities given to other problems, to the shortage of funds in more general health programmes, or to the lack of specific low reading thermometers for recording low body temperatures. $^{78}$

A prerequisite for treating low birthweight infants successfully, however, is to avoid hypothermia. Until now the use of air heated incubators, radiant heat sources, and the mother's body heat have been the only methods available. The first two methods are complex, expensive, and require a continuous supply of electricity; they are therefore not suitable for most developing countries. A cheap, safe, and effective compromise between a complex heat supply and the more primitive method of using the mother's skin is the heated, water filled mattress that was developed after recommendations from UNICEF and a commission in WHO. ${ }^{9}$

The main aim of the present study was to obtain information about the incidence of hypothermia among preterm infants in a neonatal care unit in a developing country. The second aim was to assess the effectiveness of rewarming low birthweight hypothermic infants on a heated, water filled mattress, by comparing them with infants nursed in an air heated incubator.

\section{Patients and methods}

The study was undertaken in the neonatal care unit in the Department of Paediatrics at Capa Hospital, Istanbul, Turkey, from February 1986 to March 1987 with an interruption during the summer months from June to September. It included infants weighing between 1000 and $2000 \mathrm{~g}$, and not older than 7 days, 
who had no serious malformations, seizures, or severe symptoms of respiratory distress requiring treatment with supplementary oxygen. Five heated, water filled mattresses were available at the neonatal care unit. Sixty infants who fulfilled the above criteria for the study were (on admission to the neonatal care unit) randomly assigned for treatment either on the heated, water filled mattress $(n=28)$, or in the incubator $(n=32)$.

Most of the babies $(68 \%)$ came from the Capa Hospital delivery unit and were carried there by a parent, which took about five minutes. Sixteen babies $(27 \%)$ were transported by car from other city delivery units located not more than $\mathbf{4 5}$ minutes away. Three babies $(5 \%)$ arrived directly from their homes. During transportation the traditional swaddling was used with cotton sheets and a blanket. No transport incubator was available. The gestational age of the newborn infants was evaluated by Finnström's postnatal maturity method. ${ }^{10}$

The characteristics of the groups on admission are shown in the table. There were no significant differences between the groups in body weight or length, head or mid arm circumference, or gestational age.

The heated, water filled mattress was designed by Kanthal Medical Heating AB, in collaboration with paediatricians at the Huddinge Hospital. It consists of a polyvinyl chloride bag filled with 10 litres of water. The mattress is heated by a pad including a

Table Characteristics of infants on admission to the neonatal care unit. Values expressed as mean (SEM) except where otherwise stated

\begin{tabular}{|c|c|c|}
\hline & $\begin{array}{l}\text { Infants treated } \\
\text { on heated, } \\
\text { water filled } \\
\text { mattress } \\
(n=28)\end{array}$ & $\begin{array}{l}\text { Infants treated } \\
\text { in incubator } \\
(n=32)\end{array}$ \\
\hline Age (hours) & $33(11 \cdot 5)$ & $21(6 \cdot 7)$ \\
\hline Weight $(\mathrm{g})$ & $1504(40)$ & $1517(51)$ \\
\hline Range & 1110-1900 & $1050-2000$ \\
\hline Length (cm) & $41 \cdot 5(0 \cdot 5)$ & $41 \cdot 3(0 \cdot 4)$ \\
\hline Head circumference $(\mathrm{cm})$ & $28.9(0.3)$ & $28.5(0.3)$ \\
\hline Mid arm circumference (cm) & $7 \cdot 6(0 \cdot 1)$ & $7 \cdot 8(0 \cdot 2)$ \\
\hline Gestational age (weeks) & $32(0.5)$ & $32(0.5)$ \\
\hline Range & $28-35$ & $27-36$ \\
\hline $\begin{array}{l}\text { Rectal temperature on } \\
\text { admission }\left({ }^{\circ} \mathrm{C}\right)\end{array}$ & $34.4(0.3)$ & $\begin{array}{l}34 \cdot 2(0.3) \\
30.6-37.0\end{array}$ \\
\hline \multicolumn{3}{|l|}{ Axillary temperature on } \\
\hline $\begin{array}{l}\text { admission }\left({ }^{\circ} \mathrm{C}\right) \\
\text { Range }\end{array}$ & $\begin{array}{l}34 \cdot 1(0 \cdot 2) \\
30 \cdot 7-35 \cdot 9\end{array}$ & $\begin{array}{l}33 \cdot 9(0 \cdot 3) \\
30 \cdot 2-36 \cdot 6\end{array}$ \\
\hline No (\%) of infants who died & $6(21)$ & $11(34)$ \\
\hline Mean age (days) & 7 & 4 \\
\hline \multicolumn{3}{|l|}{ Rectal temperature on } \\
\hline
\end{tabular}

None of the differences is significant. heating foil. It is covered with plastic and contains five built in thermistors. Two of the thermistors regulate the temperature, two are safety controls (to avoid overheating), and one records the temperature of the heated, water filled mattress on a digital display. The heating pad is supplied by 24 volts/AC with a maximum power of 50 watts. The temperature can be regulated in seven steps between $35^{\circ} \mathrm{C}$ and $38^{\circ} \mathrm{C}$; overheating as well as underheating alarms are built in. When the electricity supply is interrupted the alarm rings. ${ }^{9}$ The mattress is placed in the crib. Infants are dressed in a nappy, cotton shirt, and a dress. Infants weighing less than $1500 \mathrm{~g}$ wear a cotton cap as well. Each infant is placed on the mattress and covered with a blanket.

The incubators used in the neonatal care unit in Istanbul are standard models available on the ward (Draeger-6000 and Vickers-Medical Model 59). They are all single walled, manually controlled, and air heated. In the incubator the infant wears only a nappy. During the rewarming period after admission the mean (SEM) temperature setting of the heated, water filled mattress is $37(0.1)$ to $38(0.1)^{\circ} \mathrm{C}$ and that of the incubators is the highest temperature that the incubator can provide- $35(0.4)^{\circ} \mathrm{C}$. After rewarming, the temperatures of the devices are set in accordance with the infant's rectal temperature and with the aim of obtaining a normal temperature of $36 \cdot 5$ to $37 \cdot 5^{\circ} \mathrm{C}{ }^{11}$

The rectal temperature is measured $2 \mathrm{~cm}$ up the rectum by a 'low-reading' mercury thermometer designed for premature infants with a range between $27^{\circ}$ and $41^{\circ} \mathrm{C}$. The thermometers were tested by comparing them with a certified mercury thermometer which was placed in a water bath with a temperature between $30^{\circ}$ and $40^{\circ} \mathrm{C}$, and only those that were found to be accurate within $0.1^{\circ} \mathrm{C}$ were accepted. The axillary temperature was measured with an electronic thermometer of $0.1^{\circ} \mathrm{C}$ accuracy (Crafttemp) ${ }^{12}$ at the same time as the rectal temperature. The axillary thermometer's disposable sensor was placed at the apex between the anterior and posterior margins of the axilla. The rectal and axillary temperatures were recorded on admission, and then twice daily between 7 and 8 am and again between 2 and $3 \mathrm{pm}$.

The air temperature of the incubator was recorded by the standard thermometer inside the incubators. The air temperature of the room was measured with a standard mercury thermometer. The water temperature of the heated, water filled mattress was recorded from the digital display of the unit. All measurements were performed by a nurse specially engaged for this study and the temperatures were measured twice a day.

All the infants were gavage fed either breast milk, 
or premature infant formula (Preaptamil, Milupa) if the mother could not produce enough breast milk. Body weight was measured on a standard baby scale sensitive to differences of $5 \mathrm{~g}$; body length was measured in the supine position on a wooden scale, and head circumference and mid/upper arm circumference were measured with a standard tape. All measurements were made for every infant on admission to the neonatal care unit.

Mothers who were available during the first 24 hours after admission (26 of 60 ) were asked for their views about the mattress or incubator by a psychologist (DT), on the first day, and after one week of treatment.

The results are presented as mean (SEM) and range, the quantitative differences between the groups were calculated by the unpaired $t$ test (one tail), and the frequency differences by $\chi^{2}$ analysis. For regression analysis the method of least squares was used. A p value of less than 0.05 was considered significant.

\section{Results}

On admission most of the infants were hypothermic (table). Of 60 babies $53(88 \%)$ had rectal temperatures below $36^{\circ} \mathrm{C}$, and seven babies $(12 \%)$ had rectal temperatures below $32^{\circ} \mathrm{C}$ (fig 1). Severe hypothermia $\left(\leqslant 34^{\circ} \mathrm{C}\right)$ occurred regardless of place of birth $(24 \%$ of babies born at Capa Hospital, and $63 \%$ of babies born in other delivery units) or season of the year (32\% during December to February, and 39\% during March to May). No significant correlation was found between the degree of hypothermia and the infants' age, birth weight, or gestational age.

When rectal and axillary temperatures were measured simultaneously good agreement was found between the two measurements (fig 2).

The results of rewarming the infants during the first three days after admission are shown in fig 3. There was a significant difference between the two treatment groups in the rectal temperatures. Infants treated on the heated, water filled mattresses were normothermic on the first day after admission and continued to have stable normal rectal temperatures on subsequent days. On the other hand hypothermia persisted in the infants treated in the air heated incubators and these infants did not become normothermic until the third day of treatment. The mean air temperature in the incubator was $33(0.5)^{\circ} \mathrm{C}$ on the first day $(n=32), 34.5(0.3)^{\circ} \mathrm{C}$ on the second day $(n=31)$, and $34.7(0.4)^{\circ} \mathrm{C}$ on the third day $(n=24)$. The mean room air temperature during the treatment of all babies was $24.5(0.3)^{\circ} \mathrm{C}$ on the first day, $24.7(0.2)^{\circ} \mathrm{C}$ on the second day, and $24.8(0 \cdot 3)^{\circ} \mathrm{C}$ on the third day.

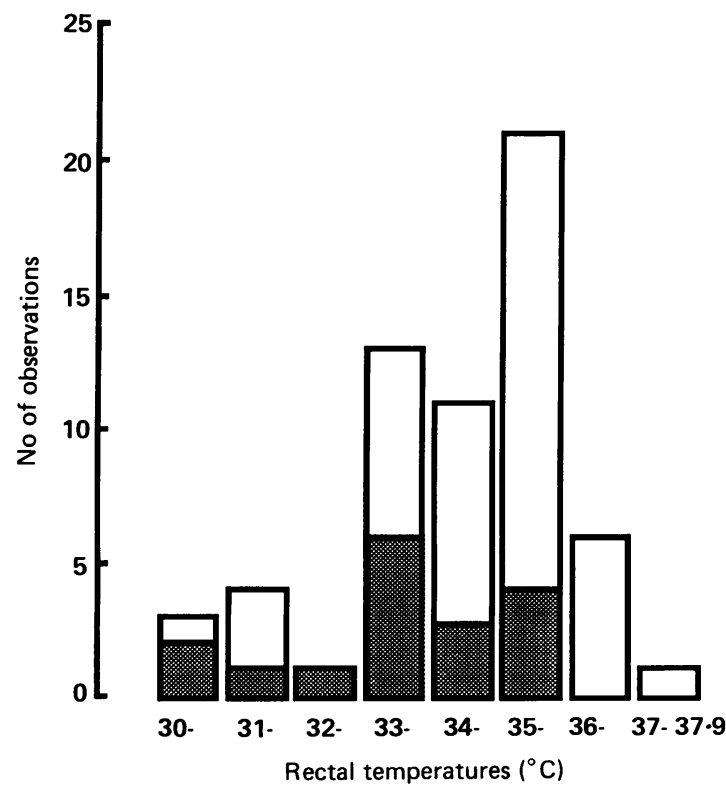

Fig 1 Rectal temperature in 60 newborn low birthweight infants on admission to neonatal care unit. Shaded areas represent infants who died after admission.

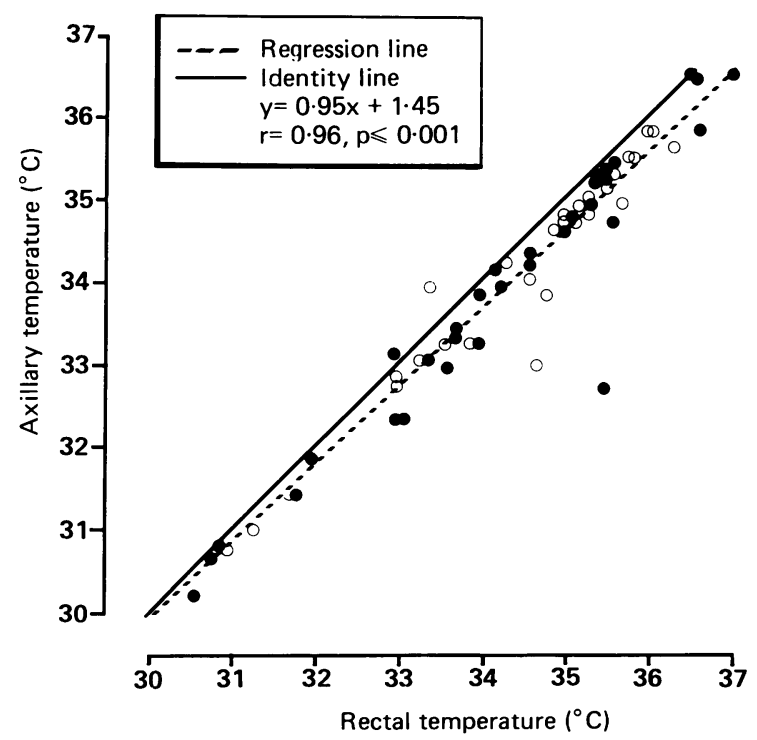

Fig 2 Correlation between rectal temperature and axillary temperature in 60 infants on admission to the neonatal care unit. Open circles represent infants treated on heated, water filled mattresses; closed circles represent infants treated in incubators. 


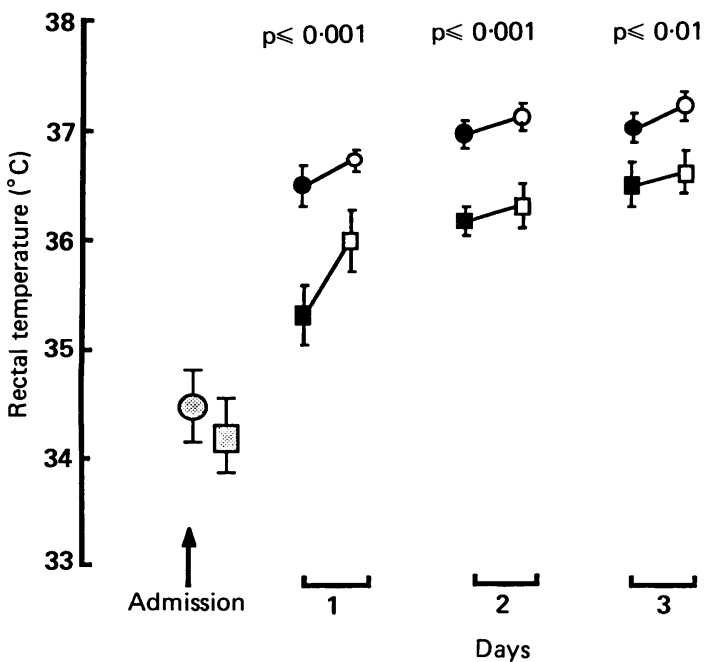

Fig 3 Rewarming low birthweight infants during the first three days after admission to the neonatal care unit. Values are given as mean (SEM). Filled symbols indicate morning temperature, open symbols indicate afternoon temperature. $\square=$ Treatment in incubator ( $n$ at day $1=32$, at day $2=31$, at day $3=24) ; \bigcirc$ Treatment on heated, water filled mattress ( $n$ at day $1=28$, at day $2=27$, at day $3=25$ ).

A detailed analysis of the course of rewarming in four hypothermic infants (with rectal temperatures between $33^{\circ} \mathrm{C}$ and $34.2^{\circ} \mathrm{C}$ ) on the heated, water filled mattress and one infant in the incubator is shown in fig 4 . The rectal temperatures were recorded every 10 minutes. The temperature of the mattress was $37.5^{\circ} \mathrm{C}$ and of the incubator air $35^{\circ} \mathrm{C}$. All four infants on the heated, water filled mattress achieved a rectal temperature of $36^{\circ} \mathrm{C}$ after 1.5 hours of rewarming; the infant in the incubator achieved a rectal temperature of $35.2^{\circ} \mathrm{C}$ after two hours.

Of 60 infants investigated during the study, 17 babies $(28 \%)$ died after admission. In the heated, water filled mattress group, six of 28 infants $(21 \%)$ died and in the incubator group 11 of 32 infants (34\%) died. On admission, the mean rectal temperature of the infants who died was $33.7^{\circ} \mathrm{C}$ in the heated, water filled mattress group and $33.4^{\circ} \mathrm{C}$ in the incubator group (table). The main cause of neonatal death was probably infection, but no necropsies could be carried out. Breast feeding was encouraged on the ward. Among the 43 infants who survived the immediate neonatal period, 18 of 22 infants in the study group (82\%), and 14 of 21 in the control group $(71 \%)$ were being breast fed on discharge; this difference is not significant.

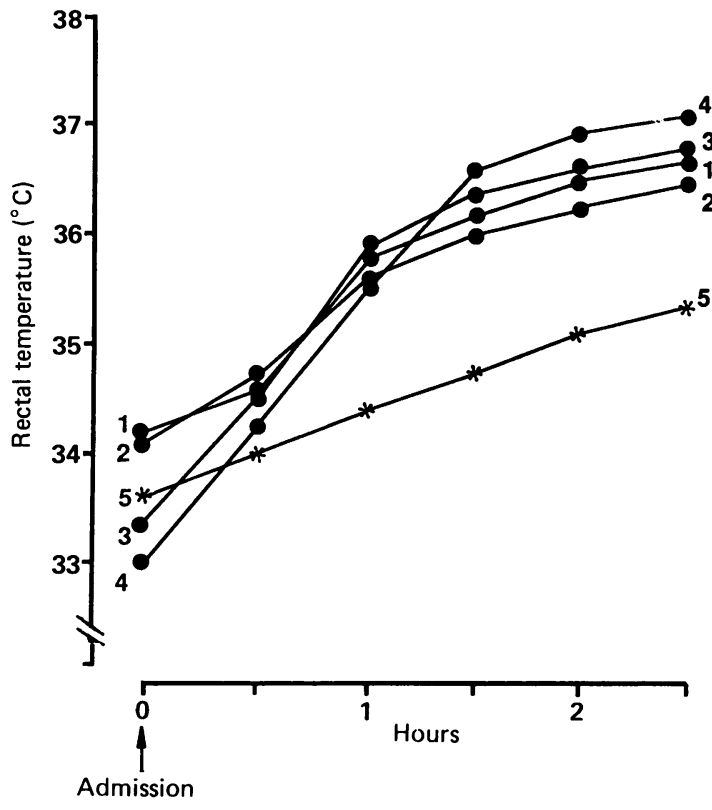

Fig 4 Rewarming of five hypothermic infants. Cases 1-4 were rewarmed on the heated, water filled mattress and case 5 was rewarmed in the incubator. Body weight and admission age of case 1: $1100 \mathrm{~g}, 24$ hours; case 2: $1270 \mathrm{~g}$, not known; case 3: $1150 \mathrm{~g}, 2$ hours; case 4: $1360 \mathrm{~g}, 17$ hours; case 5: $1265 \mathrm{~g}, 4$ hours.

\section{Discussion}

Only a few reports from developing countries on the incidence of hypothermia in low birthweight infants are available. Tafari from Ethiopia reported a high incidence of hypothermia (67\%) in low birthweight infants on admission to the special care unit, and showed that in all birthweight categories there was a linear increase in neonatal mortality with falling body temperature. ${ }^{7}$ No such report has come from Turkey.

The present study confirms that neonatal hypothermia in newborn low birthweight infants in developing countries is common. One reason why it is not recognised is that the lowest temperature that can be read on ordinary thermometers is $34^{\circ} \mathrm{C}$ and these thermometers are widely used. Infants with rectal temperatures below $34^{\circ} \mathrm{C}$ constituted $35 \%$ of all admitted infants to our study, and could not have been identified without the use of low reading thermometers.

There are good reasons to believe that the principal cause of the high incidence of hypothermia among preterm babies in our study is inappropriate 
handling of them immediately after birth. We studied 13 newborn babies born at full term after uncomplicated deliveries in the obstetric department at Capa Hospital in March 1987, and found that their rectal temperatures dropped to $35 \cdot 2(0 \cdot 1)^{\circ} \mathrm{C}$ at 30 minutes after birth and rose to $35.5(0.2)^{\circ} \mathrm{C} 2$ hours later in a room temperature of $25(0.3)^{\circ} \mathrm{C}$. The reason for this heat loss was the absence of routines for drying the babies thoroughly and using the mother as an external heat source (I Sarman, G Can, unpublished observations). These findings confirm previous reports. ${ }^{13}$ Most premature babies underwent similar procedures. The few available incubators in the nursery were old and ineffective for warming babies. By immediately drying and wrapping the newborn infant, and by using the mother's body heat in skin to skin contact as a heat source we believe it is possible to prevent neonatal hypothermia effectively.

Several investigations have shown close agreement between axillary and rectal temperatures in newborn, and especially in preterm, infants. ${ }^{14} 15$ These measurements were made in normothermic babies but the results of our study in hypothermic preterm infants accord with these findings. Measurements of axillary temperature can therefore replace measurements of rectal temperature in such infants.

We have previously studied the thermal response of normothermic low birthweight infants in a prospective randomised controlled study by comparing the heated, water filled mattress treatment to treatment in an air heated incubator. No significant differences between the groups were found in minimal oxygen consumption, skin and rectal temperatures, and daily weight gain. ${ }^{16}$ On the other hand the present investigation shows that the hypothermic infants were rewarmed more rapidly on the heated, water filled mattress than in the air heated incubator. One of the reasons for this may be the higher and more stable environmental temperature and the more effective heat conduction of the water in the heated, water filled mattress. When the electricity supply fails the high heat capacity of 10 litres of water keeps the water warm for several hours. The method of recording the incubator air temperature intermittently (twice daily in our study) is not enough for an analysis of the entire period of heating by the incubator. The presetting of an incubator temperature does not mean that the desired environmental temperature is kept constant in the air heated incubator during one day; the temperature immediately falls when the electricity supply is cut off. This happened almost every day during the present study, and it happens in most developing countries. The incubator needs to be operated by trained staff, and the portholes and doors must be completely closed to maintain a high air temperature. The neonatal care unit had only one full time nurse in the daytime. During the nights the one nurse available was on duty in at least one more unit. The responsibility for the care of the infants was therefore largely assumed by the mothers who were shown how to operate the warming equipment and supervise their infants. The mothers generally arrived late at the neonatal care unit after delivery because it took a long time to mobilise them and the hospital staff gave little help. The care of the babies whose mothers could not take care of them on the first days on the neonatal care unit was then primarily taken over by other mothers or relatives. This may further explain the incorrect changes in the incubator temperatures during the first days after admission that resulted in persistent hypothermia. It seems possible that the temperature of the equipment might be better regulated by allowing untrained mothers to feel the conductive heat by touching the warm water of a mattress instead of regulating the air temperature after reading a figure on a thermometer scale.

The plexiglass cover of the incubator hinders the mother's access to her child. A mother who delivers a premature infant suffers complete deprivation from the first day, and severe deprivation from then until the eighth week, if she can only see her child through a glass wall. ${ }^{17}$ The care of a newborn infant on the heated, water filled mattress raises no such obstacle. Among the 26 mothers who were interviewed, the mothers of the infants treated on the heated, water filled mattress (14 of 15) greatly preferred the use of the mattress, which made it possible for them to touch their babies (I Sarman, G Can, D Toparlak, unpublished observations). Only one of 11 of the mothers of the incubator group preferred it. The heated, water filled mattress treatment probably strengthens early mother/infant bonding.

We suggest that every effort should be made to prevent hypothermia by early drying and by wrapping the newborn baby and giving it to the mother for close skin to skin contact. We believe that use of the heated, water filled mattress is more appropriate than the use of air heated incubators in rewarming babies when there are few-if any-qualified staff available to operate the more complicated air heated incubator.

This project was supported by a grant from the Swedish Medical Research Council (No 19X-06963-01). We thank psychologist Derya Toparlak in the department of paediatrics in Capa Hospital, Istanbul, who interviewed the mothers.

\footnotetext{
References

1 Budin P. The nursling. London: Caxton Publishing, 1907.

2 Silverman WA, Fertig JW, Berger AP. The influence of the
} 
thermal environment upon the survival of newly born premature infants. Pediatrics 1958;22:876-85.

${ }^{3}$ Brück $K$. Temperature regulation in the newborn infant. Biologia Neonatorum 1961;3:65-119.

4 Hey EN, Katz G, O'Connell B. The total thermal insulation of the newborn baby. J Physiol 1970;207:638-98.

5 Tafari N, Olsson EE. Neonatal cold injury in the tropics. Ethiop Med J 1973;11:57-64.

${ }^{6}$ Santosh KB, Sudershan K, Hari MKS, Shymal KS, Shant G. Primary cold injury in the newborn. Indian Pediatr 1971;8: 827-30.

7 Tafari N. Hypothermia in the tropics: epidemiologic aspects. Swedish Agency for Research Cooperation with Developing Countries 1985;R2:53-8.

8 Tafari N, Gentz J. Aspects of rewarming newborn infants with severe accidental hypothermia. Acta Paediatr Scand 1974;63: 595-600.

9 Tunell R, Sarman I. The water-filled heated mattress. An alternative to incubator care in developed and developing countries? In: Rolfe P, ed. Neonatal physiological measurements. London: Butterworth, 1986:419-23.

${ }^{10}$ Finnström O. Studies on maturity in newborn infants. II. External characteristics. Acta Paediatr Scand 1972;61:24-32.
11 Hey EN, Katz G. The optimum thermal environment for naked babies. Arch Dis Child 1970;45:328-34.

12 Fleming M, Håkansson $\mathrm{H}$, Svenningsen NW. A disposable new electronic temperature probe for skin temperature measurements in the newborn infant nursery. Int J Nurs Stud 1983;20: 89-96.

13 Dahm LS, James LS. Newborn temperature and calculated heat loss in the delivery room. Pediatrics 1972;49:504-13.

14 Torrance JT. Temperature readings of preterm infants. Nurs Res 1968;17:312.

15 Mayfield SR, Bhatia J, Nakamura KT, Rios GR, Bell EF. Temperature measurement in term and preterm neonates. J Pediatr 1984;104:271-5.

${ }^{16}$ Sarman I, Tunell R. Providing warmth for preterm babies by a heated, water filled mattress. Arch Dis Child 1989;64:29-33.

${ }_{17}$ Marshall HK, Kennell HJ. Mothers separated from their newborn infants. Pediatr Clin North Am 1970;17:1015-37.

Correspondence and requests for reprints to Dr I Sarman or Professor R Tunell, Department of Paediatrics, Huddinge Hospital, S-141 86 Huddinge, Sweden.

Accepted 26 October 1988 